\title{
Management Practices in a Formal Design Process for a Metro Project in Doha, Qatar
}

\author{
Paul James \\ Graduate School Bangkok University, Bangkok, Thailand \\ E-mail: paul.j@bu.ac.th
}

Received: April 4, 2015 Accepted: May 11, $2015 \quad$ Published: July 1, 2015

doi:10.5296/jmr.v7i4.7513 URL: http://dx.doi.org/10.5296/jmr.v7i4.7513

\begin{abstract}
This is a research paper focused on assessing the design project manager behaviour and the raised managerial design issues relating to a formal design review in a metro project start-up. Very little research has been conducted in this area and the paper exposes weak aspects of the design review process previously unexplored in today's metro construction environments.

In order to consider more implicitly the questions and issues raised, this empirical groundwork utilised an interpretive perspective. The scope for this research was the design mechanisms/processes associated with a large single package - a TBM Segment Design. The population for this study was made up of a number of individuals (12) engineers/Managers located at site, and a total of 9 Engineers/Managers were determined as the resultant sample frame.

The outcomes consisted of six (6) themes, namely: Mismanagement Issues; Management Interference; Technical Issues; Contractor Design managers Issues; Documentation Issues; Communication Issues, raised from an initial question; these were further developed into four (4) final themes relating to an assessment of the managerial implications.

The paper gives a clear insight into the practical issues surrounding a metro design review and the development of appropriate managerial strategies that can be implemented. The paper also addresses some of the implications for continuing design review developments. The paper suggests that projects of this kind may benefit from an Integrated Collaborative Design approach through integrating construction expertise with the design process at the detail design phase.
\end{abstract}

Keywords: Design review, Project management, Management, Contractor, Design process, Metro 


\section{Introduction}

The construction industry in the Doha, Qatar appears to be in a period of rapid development and expansion through the amount and magnitude - financial and coverage - of public construction projects. A project in this paper is considered to be highly complex events involving collaborative measures resulting in a sustainable build outcome incorporating many different specialists (Craig and Sommerville, 2007). However, the construction environment in developing countries is seen as riskier than in developed countries (Ezeldin and Sharara, 2006). Careful assessment of each project is therefore required to ensure that the client is satisfied (Lahn and Stevens, 2011) in terms of the buildability and constructability of each project (Chan and Chan, 2004) and clarity, visibility and transparency relating to cost and quality variables. Most design protocols calls for a streamlining of design activity that corresponds with developing more efficient reiterative design processes (Cross, 2008) that helps to focus energy on deliberate and functional aspects of the design. These are used to describe and underpin somewhat increasingly detailed design solutions to meet client requirements (Baldwin et al., 1999). In this respect, this is considered to be the key aspect of the project design process (Cockshaw, 2001). For example, the design process often requires the reduction of the design package into smaller functional segments that make it easier to develop and control - where these elements are always "delivered" as pertinent to client requirements. These client requirements are conceptualised into a model influenced by design protocols consisting of procedures, drawings and technical specifications (Freire and Alarcon, 2000). Incomplete outputs develop confused understanding of both design problems and alternative solutions (Ulrich and Eppinger, 1999) resulting from a diverse design team representing different engineering disciplines often through significant pressure on employee commitment (Kettley, 1995). However, delays due to incomplete or ineffective design outcomes (Austin et al, 1998) suggest that costs affect project performance negatively (Mitropoulos and Tatum, 2000). Few real examples exist that show the success of the virtuous application of the design review process (Lafford et al, 1998), which could illustrate simply that either project managers do not seem to learn from failure to design well (Saxon, 1998 ) or that each project manager's capability and understanding of good design practices seriously compromises the design process (Hedges et al., 1993). This leads to an insufficient understanding of the design process between often opposing players in the design arena (Karhu and Lahdenpera, 1999). It also leads to claims that a poor understanding of information flow (Newton and Hedges, 1996) adversely affects unified outcomes with buildable and sustainable designs creating unbalanced resource allocation issues (Koskela and Huovila, 1997b) resulting in client management issues through more exacting demands in terms of design outcome, time, cost (Songer et al., 2000) and quality (James, 2005). In order to drive the inquiry, question 1 was raised, how is the present employed design methodology and managerial process characterised?

Of equal concern is the assessment of the design deliverables as clients expect improved performance from their appointed Engineer (Gray and Hughes, 2001). This also suggests that clients require stakeholder management (Yang, 2009). Further, part of this requires the design to be an integrated process (Egan, 1998), which is crucial to the project success through the 
development of appropriate solutions (Mitropoulos and Tatum, 2000) leading to lower avoidable cost (Morris, Rogerson and Jared, 1999). Further, construction projects and their germane success also require contractor assessment (Alzahrani and Emsley, 2013) along with project manager - human factors assessment, which plays an important role in determining the success of a project (Yang, Huang and Wu, 2011). In terms of design verification Boehm (1984) indicates that without this stage, the design cannot effectively be implemented, and therefore is crucial to the overall strategic performance of the project.

This is a research paper focused on assessing the design project managerial behaviour and the raised managerial issues relating to a formal design review in a metro project start-up. Underpinning this paper is the notion that the construction design process is considered a highly structured form of problem solving (Lawson, 1997). Mechanisms such as "structured" often provide for managerial accountability, traceability, and personal responsibility in order to reduce corruption possibilities (James, 1996). However, design appears to be an area still neglected in construction projects (Koskela and Huovila, 1997b), is considered to be a useful strategic tool (Hargadon, 2005) and also an important contribution to innovation development (Verganti 2003). A further question 2 - was raised here, how does the management practices in a metro in Doha, Qatar affect the efficacy of the arrangements for managing large-projects and their outcomes for their clients?

\section{Methodology}

In order to develop a much broader and deeper approach surrounding the issues generated and to consider more implicitly the questions and issues raised, this empirical groundwork utilised also an interpretive approach (Walsh, White and Young, 2008) in order to reinforce "completeness" (Tesch, 1989). The scope for this research was the design mechanisms/processes associated with a large single package - the TBM Segment Design. Engineering design staff related to this package were considered specialist knowledge agents and actors (Benn et al., 2008) as their opinions and experiences influenced the development, application and effectiveness of design outcomes at site. The research used a semi-structured interview conducted with engineering staff, which provided an appropriate element of context and flexibility (Cassell and Symon, 2004) and this was further aided by applying an inductive/theory building approach (Glaser and Strauss, 1967). Given the lack of appropriately focused research in this area, this methodology is seen as suitable for creating contextual data for the purpose of forming richer theory development (Cayla and Eckhardt, 2007).

The population for this study was made up of a number of individuals (12) Engineers/Managers located at site and chosen through applying the approach of a targeted population of interest (Carman, 1990) - design-based knowledge - and this reflected the criteria of theoretical purpose, relevance and appropriateness (Glaser and Strauss, 1967) and considered adequate and appropriate for this inquiry (Guest, Bunce and Johnson, 2006; and Bryman, 2012), but it has no bearing on the research logic (Crouch and McKenzie, 2006). Using Glaser's (2004) to further substantiate the sampling process, a total of 9 
Engineers/Managers were thus determined as the resultant sample frame, which could also be considered convenience sampling according to Harrel and Fors (1995).

All relevant documentation was reviewed and the protocols and levels of engagement in the design review assessed and reported. Each interview was audio recorded for future analysis. Interviews were conducted in English and took approximately 30 minutes. The conduct of the interviews follows a similar process used by Gray and Wilcox (1995), with each individual group being asked the same set of questions - modified through ancillary questioning (probes and follow-ups) in the same way as Balshem (1991). Each interview was initially manually interrogated and coded using the Acrobat software according to sub-themes that 'surfaced' from the interview dialogue - using a form of open-coding derived from Glaser (1992a); and Straus and Corbin (1990). This treatment was also reinforced and extended through the use of thematic analysis conducted using the NVivo 11 - qualitative software package (Walsh, White and Young, 2008). Each interview was treated and coded independently. Coding refers to the process of classifying segments of text or text segments with similar content into separate categories for condensation into major themes (Silverman, 2001; Miller and Crabtree, 1999; and Glaser and Strauss, 1992), often through a cyclic process. In this way, no portion of any interview dialogue was left uncoded and the overall outcome represented the shared respondents views and documented perspectives through an evolving coding-sequence (Buston, 1999). Various themes were sensed from the use of the software packages, as well as from the initial manual-coding attempts. This dual form of interrogation was an attempt to increase the credibility and dependability (Guba, 1981; and Lincoln and Guba, 1985) of the choice of both key themes and sub-themes through a triangulation process. NVivo 11 was further used to explore these sub-themes by helping to pull together each of these sub-themes from all the interviews (Harwood and Garry, 2003). In this way, it was possible to capture each respondent's comments across transcripts and the various available documentation (Riessman, 1993) on each supported sub-theme and place them together for further consideration and analysis. The research methodology used was considered a mixed methodology approach and was determined to create the best possible narrative of the situation in question. The application of the overall research methodology produces construct validity (Healy and Perry, 2000) (based upon the realism paradigm); and preferring to use the terms of credibility and dependability which are accepted by many qualitative researchers in place of reliability by applying Guba's constructs (Guba, 2001) and leading to the Lincoln and Guba (1985) notion of "progressive subjectivity".

\section{The Research Framework}

The outline of the research outcomes for this study is shown in Figure 1 below reflecting the two research questions - following on from Buckley and Waring (2013). Qualitative research using "thematic analysis" to reduce complex notions/outcomes into themes is essentially based on grounded theory. (Boyatzis, 1998; Gomm, 2004; and Glaser and Strauss, 1967). In essence this reflects the main qualitative approach utilised in this paper for analysing data and reporting through personal interviews. The initial framework consists of six (6) main themes resulting from question 1, namely: Mismanagement Issues; Management Interference; Technical Issues; Contractor Design managers Issues; Documentation Issues; 


\section{Macrothink}

Journal of Management Research

ISSN 1941-899X

2015, Vol. 7, No. 4

Communication Issues. The second part illustrates the four (4) themes generated from question 2. Following on from this, the discussion format used in this paper reflects the respondent's voice through a streamlined and articulated approach for reporting. Consequently, the style adopted for reporting and illustrating the data is greatly influenced by Gonzalez, (2008) and also Daniels et al. (2007) and is discussed below, focusing on the raised research questions and the resultant major themes.
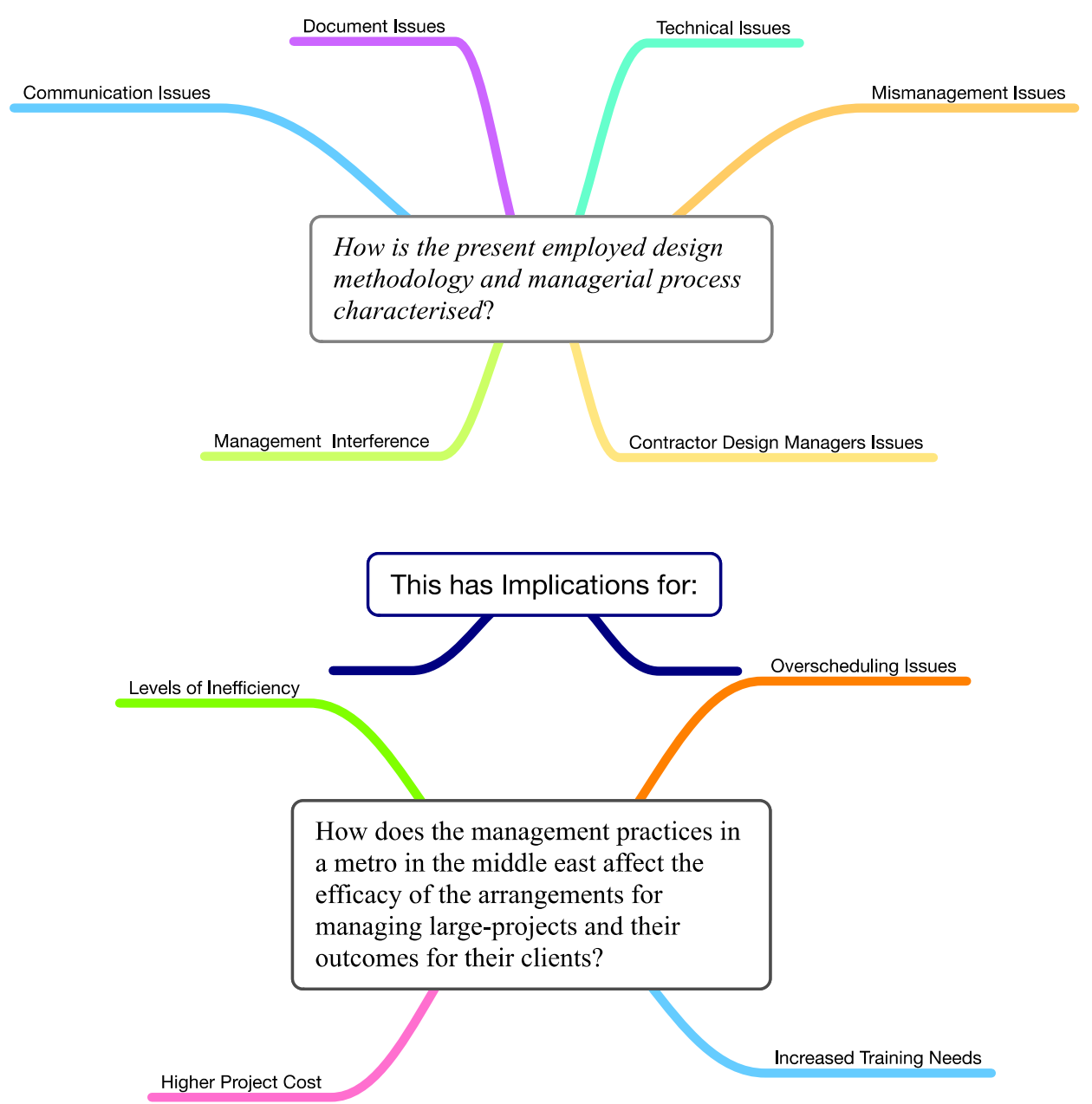

Figure 1. Design Managers Main Themes 
Table 1. Response Table

\begin{tabular}{|l|l|}
\hline \multicolumn{2}{|c|}{$\begin{array}{c}\text { Question 1 - How is the present employed design methodology } \\
\text { and managerial process characterised? }\end{array}$} \\
\hline \multicolumn{1}{|c|}{ Major Themes } & \multicolumn{1}{c|}{ No. Respondents } \\
\hline Mismanagement Issues & $2,3,4,5,6,8,9$ \\
\hline Management Interference & $2,4,5,7,8,9$ \\
\hline Technical Issues & $1,2,3,4,5,6,7,8$ \\
\hline Contractor Design Manager's Issues & $2,7,8,9$ \\
\hline Documentation Issues & $3,4,5,6,7,8$ \\
\hline Communication Issues & $1,4,5,7$ \\
\hline
\end{tabular}

Table 1 above indicates the minimum responses for each identified major theme.

\section{Discussion of Research Outcomes}

\section{Mismanagement Issues}

Using managers that were considered inexperienced or inadequately trained in design project manager has led to the issue of mismanagement. This is typified by one respondent (2) who suggested that, ...because of management, this project will be in chaos for another year at least. Nothing is recorded. It is chaos. It will waste money and we will be challenged to design appropriately and manage schedules - which at this time are more than 3 months behind schedule... Another respondent (5) suggested that, ...management don't seem to care very much. Maybe they are not really interested in the design of this metro. They haven't even determined what the TBM specifications are and they've ordered 4 of them...

Another respondent indicated (3) that ...they seem to be involved in their own little world, and don't care about us. We're just left to take the blame...

This is underpinned through the notion that the design is actually 3.5 months behind schedule in only 6 months from project start date. Given the company's stern approach to dealing with transparency, the lack of evidence securing the history of the design development appears to be a serious and severe project managerial issue.

\section{Management Interference}

This is typified by one respondent (4) who suggested that, ...design managers are running around fighting each other to get the best deal. They see only what satisfies them and not the big picture... Further, another respondent (8) indicated that, ...management consider themselves the only ones capable of managing and designing for the metro, which is ridiculous given their history here...

Significantly, there are a number of issues raised by respondents that constitute managerial interference. The first revolves around design project manager behaviour where each middle manager is deliberately given two senior managers to report to for the same job - thus breaking the scalar chain (James, 1996) leading to design process interference. 
The second issue is that two design project managers is seen to be actively competing against each other and without telling subordinate managers what they were doing when initiating meetings (Garcia et al., 2004) and without consideration of what had actually been done and thereby interfering with the normal design process.

The third issue revolved around not recording meetings (Lee, 1991) and developments and not providing a basis for ongoing design changes. This has led to misunderstandings about design changes, any underpinning of design changes, lack of schedule commitment, and also manifest confusion regarding the application of design outcomes relating directly to specified client requirements. This confusion appears to have also led to some respondents suggesting that this management led activity was a smokescreen to hide other more difficult issues financial, programming and arbitrary decisions without basis.

The fourth issue raised was that the design managers were only at site part-time. i.e. for 3 days/week without explaining to subordinate managers where they were going or what it was they were doing when not at site. This appeared to increase time pressures and actions that led to increased meetings/activities when they were on site.

\section{Technical Issues}

\section{Technical Design Outcomes}

This is typified by one respondent (7) who suggested that, ...we have the requirements in writing, but they [project managers] don't seem to know what these are... Another respondent (6) suggested that ...we keep going from one thing to another in a circle. It never ends...

After 6 months, the submission of a detailed design describing the studies carried out in developing the final designs was found missing and as such the evidence underpinning how the design specifications were built were also missing. There appeared to be difficulty in determining an adequate response from the contract designer of questions raised by the client engineer, as the focus was on repeating previously published design data of the segment design. No new material was introduced into the design review and it also became clear that where there was, it was a spurious uplift of material from other projects. Project design managers did not appear to question this.

The interviews showed that the contractor designer proposals were essentially without any form of basis - calculations were not embedded or forthcoming and did not show clear examples of directly applicable good practices. The "finalised" specifications did not determine the design outcomes, but perhaps at best specified a range of areas/items that may be considered/included in/for the final design.

The partially released specification item(s) for the TBM specifications were included but was endorsed by the design project manager as "preferential status - based on concensus". This management attitude suggests the intimation and negative engagement of Group Think (Janis, 1972).

The design project manager has not been made accountable for the delay in the development of the design - Hence the issue of schedule delays. Accordingly, the design at present as 
determined by one respondent (6) ...is incomplete, unfocused and lacks appropriate content reflecting a mono-focus on an untested design that does not offer anything except confusion, questions and delays...

\section{Design Contractor Design managers}

There does not appear to be any visibility in the design contractor's design approvals process. Without this, the design outputs cannot logically be verified as any design output requires full documentation in support, and the contract designer has not provided this. The contract designer has not determined specifications to take into consideration some of these aspects, nor underpinned their design through appropriate examples or data.

The design contractor does not appear to conform to appropriate design project manager protocols and "we are in the wind" as one respondent (4) indicated - regarding their development curve for this design.

There is a need for a co-ordination point between design contractor and management (Gray and Hughes, 2001) and there needs to be a single point of responsibility (Austin et al., 1994) but the design project manager does not seem to recognise this need. However, construction efficiency, effectiveness and costs appear to be heavily dependent on the quality of the design solution and information available (Austin et al., 2001). This notion is established through the many and myriad comments made by "every Tom Dick and Harry" who may be connected in some way to the design process. This not only increases the timescale for deliverables, but also increases the complexity of control as well as raise privacy and data protection issues.

Concensus was reported not to work in the management of the packages, as it takes time and now involves a myriad number of individuals across continents. This is underpinned by one respondent (7) who stated, ...it seems like everyone I know, knows about the issues on this project... The current strategic orientation/perspective does not appear to be able to deal with this issue.

\section{Documentation Issues}

This is typified by one respondent (4) who suggested that, ...very little is documented. No one knows what the procedures are supposed to be... Another respondent (3) suggested that ...every meeting starts with a debate about what we should be focused on. There is no ability to shake off negative feelings because it is thrust in our faces. There is nothing on paper...

\section{Documents Provided}

When documentation is produced, the document signatories are shown, but no signature found. Similarly, drawings are presented, but were all unsigned versions. This raises the issue of responsibility. Design project manager does not appear to recognise that all documents provided in a formal review setting must have been reviewed and signed appropriately so that the client can rely on the presented judgement of the design output and that the design project manager can assure that the client requirements are being met. 
Design Document Deficiencies

During an international discussion, it would appear that the contractor design team is not prepared appropriately, as there is no:

- Containment list/set of drawing titles, their numbers, revs or dates showing what was captured in the Design Review envelope was given by the design contractor. Design report determining the status of the prescriptive design or a written determination of the performance orientation for the design outcomes.

- Document stating the design outcomes relationships/connections to the client deliverables.

- Documents stating the build strength of each drawing/design outcome and how far this is from an appropriate design cut-off.

- Guidelines were not provided of any specific criteria to be employed in the preparation and implementation of the planning, design and construction of the segment design.

- Calculations underpinning elements of the designs were not provided whether electronically or in printed form nor were any suggestions as to how these may be developed in the Design Review corridor.

- Base-line data assumptions were not provided nor were any suggestions as to how these may be developed in the Design Review corridor.

- There does not appear to be any formal written historical communication documents underpinning any design development and no documentation outlining the project status on a monthly basis.

A Keystone Design activities timeline did not exist for the development of the Segment Ring, Mould Design or any other singular/specific design package attached to the metro programme.

Design Documentation - there does not appear to be continuation of design according to any specified path of development, which suggests that the entire design process outcomes are considered unsustainable, uncontrolled and demonstrably untrustworthy.

Internal review documents - no documents were created of any internal review documentation signifying who has signed, dated and authorised the release of each specific design package.

\section{Document and Document Process Considerations}

A document review indicated that there does not appear to be a document that links the documents with design outputs; nor is there an appropriate design managers Framework such as a sign-on - sign off process, for any design phase or element in the design process and therefore there is an apparent lack of transparency in this "design procedure". 
Also, there does not appear to be an internal review and approval process to satisfy to obtain approval on the choices made during the review process. The individual who reviews and approves the phase and document selection should sign and date appropriately. Determining who can do this is unclear or missing from the formal design process at present.

The culture of design development does not exist and responsibilities for advising and ensuring design development have not been nurtured or demanded by the design project manager.

The Design Contractor is considered a failing partner in the design of the Metro as it would appear that there is no instructive or cohesive "plan of design" for design deliverables. There are no documents showing what will be done and when and it further appears that the Design Contractor staff at site have no understanding of this "plan" either.

The Design Review exercise has led to the notion that drawing control protocols are non-existent and thus leads to release, reliance and non-compliance issues.

\section{Communication Issues}

\section{E-mails/Outside Contacts in the Design Process}

This is typified by one respondent (5) who suggested that, ...we have learnt to send our understanding by e-mails. It's better that way... Another respondent (7) indicated that ...communication is a problem. We meet sometimes 3 times day and its not enough...

Local and international associates appear to be contacted without discussion with other members of the design team and are not informed until the contact has been engaged. Therefore this process leads to a "loose" management of whom may be involved and does little to help understand how such contacts become partners through an "uninvolved" and "uncontrolled" process. Further, the issue of "privacy" springs up, as does compliance with established protocols in dealing with outsiders of proprietary information on the project.

The accuracy, timeliness and quality of information exchange between the project team members were poor at best (Dawood et al., 2003), which indicates quite clearly that managing information is paramount to a successful project outcome.

It was reported that there would appear to be a number of missing staff on the design team, as there is no quality management specialist input into the design mix; nor is there a risk manager; a contract specialist, an HSE specialist or QS and these would bring a more cohesive independent design process outcome.

It would appear that much of the communications was uncoordinated with uncontrolled e-mails/phone-calls being sent (internally but through unrestricted channels and across borders) that continue to raise fundamental management issues during the design process. 


\section{Discussion and Implication of Results}

Table 2. Response Table

Question 2 - How does the management practices in a metro in Doha, Qatar affect the efficacy of the arrangements for managing large-projects and their outcomes for their clients?

\begin{tabular}{|l|l|}
\hline \multicolumn{1}{|c|}{ Major Themes } & \multicolumn{1}{c|}{ No. Respondents } \\
\hline Overscheduling Issues & $1,3,4,6,8,9$ \\
\hline Increased Management Training Needs & $2,3,5,6,8$ \\
\hline Levels of Inefficiency & $1,2,4,6,7,8,9$ \\
\hline Higher Project Cost & $1,3,5,6,7,8$ \\
\hline
\end{tabular}

\section{Overscheduling Issues}

The project manager has had 6 months to develop an appropriate TBM metro design package and the design at present is considered immature (based on Preece, 1995) through lack of appropriate design leadership (Boland and Collopy, 2004), and lacking in robust character for the design of a very costly and prestigious metro project. Reasons for this include that the design partners do not take seriously the internal designs reviews required, nor do they take seriously the client requirements leading to a lack of innovation leadership (Kelley, 2001; Austin et al., 1994).

\section{Increased Management Training Needs}

The problem associated with design project managers' demonstrable failure in developing consistent design outcomes over a period of time (Lai, Honda and Yang, 2010), comes from their own inability to manage the design process; indifference to good design; and lack of adherence to specified planning/design horizons. Targeted features of the design review package have shown that the project manager has not "designed in parallel" (Ortega-Arjona, 2010) and used a "Sequential Planning process" (Azab and ElMaraghy, 2007) and as a consequence leave the timeline spread out unequivocally with missed deadlines. Further, the design managers do not show that they know how to plan the design and review of a technical design (Wiggins and McTighe, 2005) or provide an opportunity to identify sensitivity criteria for performance evaluation. As a consequence, design managers lack management responsibility, credibility, integration and the force of innovation.

\section{Levels of Inefficiency}

Of further concern are the issues raised of the design process that appears to reinforce management culpability in creating an atmosphere of confusion and lack of communication and cooperation (Olander and Landin, 2005) that are central elements for project success (Brown, Schmied and Tarondeau, 2002). This is brought about by multiple managers interfering in the design process and demanding singular outcomes that are not considered focused on client requirements and the possibility for project information being compromised or lost (Rujirayanyong and Shi, 2006), whilst failing to facilitate any necessary updates to the client requirements (Kiviniemi, 2005). 
However, as a design outcome there is no definable consensus, as the development of each specific design package leaves the total design portfolio at risk to mismanagement and time delays (Karhu and Lahdenpera, 1999). This is therefore an enormous issue for the design management, as this experience will negatively leach into further design packages if not controlled appropriately.

There does not appear to be any design planning (Gray and Hughes, 2001), which could be an effective design solution essential to improve co-ordination between disciplines and exercise managerial control over the design process (Austin, Baldwin and Newton, 1994). Further, the design project manager exhibit no systematised understanding of the design process (Kalay, Khemlani and Choi, 1998), its required outcomes, as it is characterised as an ineffective management control process. It also indicates that the design project manager is not serious about learning how to manage the design process effectively (Saxon, 1998) and this may screen their inability to understand and procure an appropriate sustainable metro design suggesting the low priority of design in project planning capability resulting from insufficient management effort or interest (Gray and Hughes, 2001).

Design managers do not appear to understand that good design thinking leads to proper design (Buxton, 2010), and this appears to be lacking, thus leading to erratic decision making (Hammond et al, 2000) and to the manifest inability and drive to create and design new alternatives (Borja de Mozota, 2003) or sustainable goals. It could also be that management have no design managers experience which leads them to make inadequate managerial decisions raising the issue of a lack of understanding of appropriate design information flow (Rujirayanyong and Shi, 2006), data dependency and resisting the application of proper planning techniques (Austin et al, 1996). Management does not appear to encourage design teams to unite or incorporate consistent responsibility (Brown, Schmied and Tarondeau, 2002) into the design process.

Of concern was the lack of health and safety considerations that appear to be missing from the design outcomes (Chileshe, 2012); the non-encouragement of teamwork between design team members (Stempfle and Badke-Schaub, 2000); or the application of appropriate risk management activities (Adnan, Jusoff, and Salim, 2008).

The design strategy does not appear to show any involvement in environmental matters impacting on the design and therefore project managers do not appear to engage in the design of the project to minimize the environmental impact through an EIR (Gillem, 2007), nor is there a published Energy Impact Statement resulting from its application to energy management standard (ISO 50001: 2011). The design approach does not appear to be approved or documented (Anikeeff and Sriram, 2008) to allow an approval, conducted in a manner that allows a stakeholder to independently assess design developments or improvements (Chung, Gross and Yu, 1999) or able to assess the efficacy of the enabled design to stated international standards.

Contracted design team members are not incorporated into the design process but are deemed necessary to improve it (Mealiea and Baltazan, 2005). There is also no assessment of their involvement and how this has contributed to building sustainability (Riley, Pexton and 
Drilling, 2003) and added value through project optimisation (Stevens, 1997) into the project design.

The current project design appears to be fragmented, insufficiently developed, poorly deployed, and couched in mediocre abstract terms (Freire and Alarcon, 2000) that are inconsistent with good project management practices.

\section{Conclusions}

Design is not a science, but good management of design practices appear to be based on a cohesive set of procedures, plans, drawings, and a level of managerial control that ensures that the client requirements are met consistently at lower costs. In many respects, the poor application of such practices by design managers in this case has led to delays in the metro project design with associated costs and scheduling issues. Consequently, the better the design processes are defined and managed, the more effectively the metro project can operate (Juric and Pant, 2008). More effective design managers could provide design outcomes that match client contractual requirements in swifter timeframes, at lower cost through considered best practice providing more robust outcomes. The project therefore may benefit from an Integrated Collaborative Design approach through integrating construction expertise with the design process at the detail design phase (Austin et al, 2001) which may lead to a more effective constructability design, with lower cost, higher quality (James, 2005) that match or exceed Client Requirements. Thus this could be seen as reducing inefficiency and costs, reducing overscheduling, and helping to focus more effectively on management training needs.

\section{References}

Adnan, H., Jusoff, K., \& Salim, M. K. (2008). The Malaysian Construction Industry's Risk Management in Design and Build. Modern Applied Science, 2(5), 27-33.

Alzahrani, J. I., \& Emsley M. W. (2013). The impact of contractors' attributes on construction project success: a post construction evaluation. International Journal of Project Management, 31, 313-322. http://dx.doi.org/10.1016/j.ijproman.2012.06.006

Anikeeff, M. A., \& Sriram V. (2008). Construction management strategy and developer performance. Engineering, Construction and Architectural Management, 15(6), 504-513. http://dx.doi.org/10.1108/09699980810916951

Austin, S. A., Baldwin, A. N., \& Newton, A. J. (1994). Manipulating data flow models of the building design process to produce effective design programmes. In Proceedings of ARCOM Conference, Loughborough, UK, 592-601.

Austin, S.A., Baldwin, A.N., \& Newton, A.J. (1996). A data flow model to plan and manage the build design process. Journal of Engineering Design, 7(1), 3-17. http://dx.doi.org/10.1080/09544829608907924 
Austin, S., Baldwin, A., Hammond, J., Murray, M., Root, D., Thomson, D., \& Thorpe, A. (2001). Design Chains: A handbook for integrated collaborative design, Thomas Telford, London, UK.

Azab A., \& ElMaraghy, H. (2007). Sequential process planning: A hybrid optimal macro-level approach. Journal of Manufacturing Systems, 26(3-4), 147-160. http://dx.doi.org/10.1016/j.jmsy.2008.03.003

Baldwin, A.N., Austin, S.A., Hassan, T.M., \& Thorpe, A. (1999). Modelling information flow during the conceptual and schematic stages of building design. Construction Management and Economics, 17(2), 155-167. http://dx.doi.org/10.1080/014461999371655

Balshem, M. (1991). Cancer, Control and Causality: Talking about Cancer in a Working-Class Community. American Ethnologist, 18(1), 152-172. http://dx.doi.org/10.1525/ae.1991.18.1.02a00070

Benn, N., Buckingham, S., Domingue, J., \& Mancini, C. (2008). Ontological Foundations for Scholarly Debate Mapping Technology. In 2nd International Conference on Computational Models of Argument (COMMA '08), Toulouse, France.

Boehm, B. (1984). Verifying and validating software requirements and design specifications. IEEE Software, 1(1), 75-88. http://dx.doi.org/10.1109/MS.1984.233702

Boland, R., \& Collopy, F. (2004). Managing as Designing, Stanford University Press, Stanford, US.

Borja de Mozota, B. (2003). Design managers: Using Design to Build Brand Value and Corporate Innovation, Allworth, New York, US.

Boyatzis, R. (1998). Transforming Qualitative Information Thematic analysis and Code Development, Sage Publications, Thousand Oaks, NY, US.

Brittan, N. (1995). Qualitative interviews in medical research. BMJ., 311, 251-253.

Brown, K., Schmied, H., \& Tarondeau, J. (2002). Success Factors in R\&D: A meta-analysis of the empirical literature and derived implications for design managers. Design Managers $\begin{array}{llll}\text { Journal. Academic } & \text { Review, } & \text { 72-87. }\end{array}$ http://dx.doi.org/10.1111/j.1948-7177.2002.tb00013.x

Bryman, A. (2012). Social Research Methods, $4^{\text {th }}$ Edition, Oxford University Press, Oxford, UK.

Buckley, C., \& Waring, M. J. (2013). Using Diagrams to Support the Research Process: Examples from Grounded Theory. Qualitative Research, 13(2), 148-172. http://dx.doi.org/10.1177/1468794112472280

Buston, K. (1999). NUD*IST in Action: its Use and its Usefulness in a Study of Chronic Illness in Young People. In Bryman A. and Burgess R.G. (Eds), Qualitative Research: Analysis and Interpretation of Qualitative Data, Sage Publications London, 183-202. 
Buxton B. (2010). Sketching User Experiences: Getting the Design Right and the Right Design: Getting the Design Right and the Right Design, Morgan Kaufmann, San Francisco, US.

Carman, J. M. (1990). Consumer Perceptions of Service Quality: An Assessment of the SERVQUAL Dimensions. Journal of Retailing, 66(1), 33-55.

Cassell, C., \& Symon, G. (2004). Essential Guide to Qualitative Methods in Organizational Research, Sage Publications, London, UK.

Cayla, J., \& Eckhardt, G. M. (2007). Asian Brands without Borders: Regional Opportunities and Challenges. International Marketing Review, 24(4), 444-456. http://dx.doi.org/10.1108/02651330710761017

Chan, A. P. C., \& Chan, A. P. L. (2004). Key performance indicators for measuring construction success. Benchmarking: An International Journal, 11(2), 203-221. http://dx.doi.org/10.1108/14635770410532624

Chileshe, N. (2012). Benefits and barriers of construction health and safety management (HSM): Perceptions of practitioners within design organisations. Journal of Engineering, Design and Technology, 10(2), 276-298. http://dx.doi.org/10.1108/17260531211241220

Chung, L. Gross D., \& Yu, E. (1999). Architectural Design to Meet Stakeholder Requirements. IFIP - The International Federation for Information Processing, 12, 545-564. http://dx.doi.org/10.1007/978-0-387-35563-4_32

Cockshaw, A. (2001). Changing Construction Culture. In: Interdisciplinary Design. In Spence, R., Macmillan, S. \& Kirby, P. (eds.), Practice, Thomas Telford, London, UK, 15-21.

Craig, N., \& Sommerville, J. (2007). Records Management and Information Processing on Construction Sites Using Digital Pen and Paper. Records Management Journal, 17(3), 201-215. http://dx.doi.org/10.1108/09565690710833107

Cross D. (2008), Engineering Design Methods: Strategies for Product Design, Wiley, London, UK.

Crouch, M., \& McKenzie, H. (2006). The logic of small samples in interview-based qualitative research. Social Science Information, 45(4), 483-499. http://dx.doi.org/10.1177/0539018406069584

Daniels et al. (2007). The Successful Resolution of Armed Hostage/Barricade Events in Schools: A Qualitative Analysis. Psychology in the Schools, 44(6), 601-613. http://dx.doi.org/10.1002/pits.20250

Dawood, N., Sriprasert, E., Mallassi, Z., \& Hobbs, B. (2003). Development of an integrated information resource base for $4 \mathrm{D} / \mathrm{VR}$ construction processes simulation. Automation in Construction, 12, 123-131. http://dx.doi.org/10.1016/S0926-5805(02)00045-6

Egan, J., (1998). Rethinking Construction: the report of the construction task force, Department of the Environment, Transport and the Regions, London, UK. 
Erlandson, D. A., Harris, E. L., Skipper, B. L., \& Allen, S. D. (1993). Doing naturalistic inquiry: A guide to methods, Sage Publications, Thousand Oaks, CA, US.

Ezeldin, A., \& Sharara, L. (2006). Neural networks for estimating the productivity of concerting activities. Journal of Construction Engineering and Management, 132(6), 650-656. http://dx.doi.org/10.1061/(ASCE)0733-9364(2006)132:6(650)

Freire, J., \& Alarcon, L. F. (2000). Achieving a Lean Design Process. In Proceedings of Conference of the 8th International Conference for Lean Construction, Brighton, England, UK.

Garcia A., Kunz J., Ekstrom M., \& Kiviniemi A. (2004). Building a project ontology with extreme collaboration and virtual design and construction. Advanced Engineering Informatics, 18(2), 71-83. http://dx.doi.org/10.1016/j.aei.2004.09.001

Gillem, L. (2007). The Green Church. ARCC Journal, 4(2), 27-34.

Glaser, B. G., \& Strauss, A. L. (1967). The Discovery of Grounded Theory: Strategies for Qualitative Research, Aldine, Chicago, US.

Glaser, B., \& Strauss, A. (1992). The Discovery of Grounded Theory, Aldine, New York, US.

Glaser, B. G. (1992a). Basics of Grounded Theory Analysis: Emergence vs. Forcing, Sociology Press, Mill Valley, CA, US.

Glaser, B. G. (2004). Remodeling Grounded Theory. The Grounded Theory Review: An international Journal, 4(1), 1-24.

Gomm, R. (2004). Social Research Methodology: A Critical Introduction, Palgrave Macmillan, New York, US.

Gonzalez, C. (2008). Conceptions of, and approaches to, teaching online: a study of lecturers teaching postgraduate distance courses", Higher Education, 57(3), 299-314. http://dx.doi.org/10.1007/s10734-008-9145-1

Gray, C., \& Hughes, W. (2001). Building Design Managers, Butterworth Heinemann, Oxford, UK.

Gray, J., \& Wilcox, B. (1995). Good Schools, Bad Schools, Open University Press, UK.

Guba, E. G. (1981). Criteria for assessing the trustworthiness of naturalistic inquiries. Educational Communication and Technology Journal, 29, 75-91.

Hammond, J., Choo, H. J., Austin, S., Tommelein, I. D., \& Ballard, G. (2000). Integrating design planning, scheduling, and control with Deplan. In Proceedings of the $8^{\text {th }}$ International Group for Lean Construction Conference, Brighton, England, UK.

Guest, G., Bunce, A., \& Johnson, L. (2006). How Many Interviews Are Enough? An Experiment with Data Saturation and Variability. Field Methods, 18(1), 59-82. http://dx.doi.org/10.1177/1525822X05279903 
Hargadon, A. (2005). Leading With Vision: The Design of New Ventures. Design Managers Review, 16(1), 33-39. http://dx.doi.org/10.1111/j.1948-7169.2005.tb00005.x

Harrel, G. D., \& Fors, M. F. (1995). Marketing services to satisfy internal customers. $\begin{array}{llll}\text { Logistics } \quad \text { Information } & \text { Management, }\end{array}$ http://dx.doi.org/10.1108/09576059510091887

Harwood, T. G., \& Garry, T. (2003). An Overview of Content Analysis. The Marketing Review, 3(4), 479-498. http://dx.doi.org/10.1362/146934703771910080

Healy, M., \& Perry, C. (2000). Comprehensive criteria to judge validity and reliability of qualitative research within the realism paradigm. Qualitative Market Research: An International Journal, 3(3), 118-126.

ISO 50001: 2011. Energy Management Systems, International Organization for Standardization, Geneva, Switzerland.

James, P. (1996). Total Quality Management: An Introductory Text, Prentice Hall, London, UK.

James, P. (2005). Total Quality Management in Asia: Practices for the 21st Century, Pearson/Prentice Hall, Singapore.

Janis, I. L. (1972). Victims of groupthink: A psychological study of foreign-policy decisions and fiascoes. Houghton Mifflin, Oxford, UK.

Juric, M. B., \& Pant, K. (2008). Business Process Driven SOA using BPMN and BPEL: From Business Process Modeling to Orchestration and Service Oriented Architecture, Packt Publishing, Birmingham, UK.

Karhu, V., \& Lahdenpera, P. (1999). A formalised process model of current Finnish design and construction practice. The International Journal of Construction Information Technology, 7(1), 51-71.

Kalay, Y. E., Khemlani, L. \& Choi, J. W. (1998). An integrated model to support distributed collaborative design of buildings. Automation in Construction, 7(2-3), 177-188.

Kelley, P. (2001). The Art of Innovation: Lessons in Creativity from IDEO, Crown Business, New York, US.

Kettley, P. (1995). Is flatter better? Delayering the management hierarchy, The Institute of Employment Studies, Report 290, UK.

Kiviniemi, A. (2005). Requirements Management Interface to Building Product Models, \#161, Stanford University, CIFE, US.

Koskela, L., \& Huovila, P. (1997b). On the foundations of concurrent engineering. In Anumba, C.J. \& Evbuomwan, L. (Ed), $1^{\text {st }}$ International Conference on Computing in Structural Engineering, N.F.O, Institution of Structural Engineers, London. 3-4 July. 
Lafford, G., Penny, C., O’Hana, S., Scott, N., Tulett, M., \& Buttfield, A. (1998). Managing the Design Process in Civil Engineering Design and Build - a guide for Clients, Designers and Contractors, Funders Report $\mathrm{CP} / 59$, Construction Industry Research and Information Association, London, UK.

Lahn, G., \& Stevens, P. (2011). Burning oil to keep cool: The hidden energy crisis in Saudi Arabia, Chatham House, London, UK.

Lai J., Honda T., \& Yang M. C. (2010). A study of the role of user-centered design methods in design team projects. Artificial Intelligence for Engineering Design, Analysis and Manufacturing, 24(3), 303-316. http://dx.doi.org/10.1017/S0890060410000211

Lawson, B. (1997). How Designers Think, The Architectural Press Ltd, London, UK.

Lee, J. (1991). Extending the Potts and Bruns model for recording design rationale. In Proceedings of the 13th International Conference on Software Engineering, 114-125. http://dx.doi.org/10.1109/ICSE.1991.130629

Lincoln, Y. S., \& Guba, E. G. (1985). Naturalistic inquiry, Sage, Beverly Hills, US.

Mackenzie, N., \& Knipe, S. (2006). Research dilemmas: Paradigms, methods and methodology. Issues In Educational Research, 16(2), 193-205.

Malterud, K. (2001). Qualitative research: standards, challenges, and guidelines. Lancet, Aug 11, 358(9280), 483-488. PMID-11513933.

Maya, N. \& Pope C. (1995). Rigour and qualitative research. BMJ, 311, 109-112.

Mealiea, L., \& Baltazan, R. (2005). A Strategic Guide for Building Effective Teams. Public Personnel Management, 34(2), 141-160. http://dx.doi.org/10.1177/009102600503400202

Miller, W., \& Crabtree, B. (1999). The dance of interpretation. In Crabtree, B. \& Miller, W. Eds, Doing Qualitative Research. $2^{\text {nd }}$ Edn, Sage, Thousand Oaks, California, US, 127-43.

Mitropoulos, P., \& Tatum, C. B. (2000). Management-driven integration. Journal of Management in Engineering, 16(1), 48-58. http://dx.doi.org/10.1061/(ASCE)0742-597X(2000)16:1(48)

Morris, J., Rogerson, J., \& Jared, G. (1999). A tool for modelling the briefing and design decision making processes in construction, School of Industrial and Manufacturing Science, Cranfield University, Cranfield, UK.

Newton, A., \& Hedges, I. (1996). The improved planning and management of multidisciplinary building design. CIBSE / ASHRAE Joint National Conference, London.

Olander S., \& Landin, A. (2005). Evaluation of stakeholder influence in the implementation of construction projects. International Journal of Project Management, 23(4), 321-328. http://dx.doi.org/10.1016/j.ijproman.2005.02.002

Onwuegbuzie, A. J., \& Leech, N. L. (2007). Sampling Designs in Qualitative Research: Making the Sampling Process More Public. The Qualitative Report, 12(2), 238-254. 
Ortega-Arjona J. L. (2010). Patterns for Parallel Software Design, Wiley, London, UK.

Preece, A. (1995). Towards a Quality Assessment Framework for Knowledge-Based Systems. Journal of Systems and Software, 29(3), 219-234. http://dx.doi.org/10.1016/0164-1212(94)00106-W

Reisman, C. K. (1993). Narrative Analysis, Sage, London, UK.

Riley, D., Pexton K. \& Drilling, J. (2003). Procurement of sustainable construction services in the United States: the contractor's role in green buildings. UNEP Industry and Environment, 66-71, April-September.

Rujirayanyong, T., \& Shi, J. J. (2006). A project-oriented data warehouse for construction. Automation in Construction, 15(6), 800-807.

Sandelowski, M. (1995). Sample size in qualitative research. Res. Nurs. Health, 18, 179-183. http://dx.doi.org/10.1002/nur.4770180211

Saxon, R. (1998). Response from the industry. In Conference of the Design and Build Foundation, BAFTA, London, $21^{\text {st }}$ October 1998.

Silverman, D. (2001). Interpreting Qualitative Data: Methods for Analysing Talk, Text and Interaction, $2^{\text {nd }}$ Edn. Sage, London, UK.

Songer, A. D., Diekmann, J., Hendrickson, W., \& Flushing, D. (2000). Situational Re-engineering: Case Study Analysis. Journal of Construction Engineering and Management, 126(3), 185-190. http://dx.doi.org/10.1061/(ASCE)0733-9364(2000)126:3(185)

Stevens, D. (1997). Strategic Thinking: Success Secrets of Big Business Projects, McGraw-Hill, Sydney, Australia.

Strauss, A. L., \& Corbin, J. (1990). Basics of Qualitative Research: Grounded Theory, Procedures and Techniques, Sage, Newbury Park, Chicago, US.

Stempfle, J., \& Badke-Schaub, P. (2000). Thinking in design teams - an analysis of team communication. Design Studies, 23(5), 473-496. http://dx.doi.org/10.1016/S0142-694X(02)00004-2

Tesch, R. (1989). Computer software and qualitative analysis: a reassessment. In McCartney, J., \& Brent, E. (Eds.), New Technology in Sociology: Practical Applications in Research and Work, New Brunswick, New Jersey US, Transactions, 141-154.

Ulrich, K. T., \& Eppinger, S. D. (1999). Product design and development, $2^{\text {nd }}$ Edition, McGraw Hill, New York, US.

Verganti, R. (2003). Design as brokering of languages: Innovation strategies in Italian firms. Design Managers Journal, 34-42. http://dx.doi.org/10.1111/j.1948-7169.2003.tb00050.x 


\section{Macrothink}

Journal of Management Research

ISSN 1941-899X 2015, Vol. 7, No. 4

Walsh, S. P., White, K. M., \& Young, R. M. (2008). Over-Connected? A Qualitative Exploration of the Relationship between Australian Youth and Their Mobile Phones. Journal of Adolescence, 31(1), 77-92. http://dx.doi.org/10.1016/j.adolescence.2007.04.004

Wiggins, G. P., \& McTighe, J. (2005). Understanding by Design, Association of Supervision and Curriculum Development, Alexandria, VA, US.

Yang, L. R., Huang C. F., \& Wu K. S. (2011). The association among project manager's leadership style, teamwork and project success. International Journal of Project Management, 29, 258-267. http://dx.doi.org/10.1016/j.ijproman.2010.03.006

Yang, J., Shen, G. Q., Ho, M., Drew, S. D., \& Chan, A. P. C. (2009). Exploring critical success factors for stakeholder management in construction projects. Journal of Civil Engineering and Management, http://dx.doi.org/10.3846/1392-3730.2009.15.337-348

15(4),

337-348. 